\title{
Doing Theatre: Theatre Pedagogy through the Folktale
}

\author{
Jean Small \\ Professor Emerita, UWI \\ Kingston, Jamaica \\ jsjeansmall@gmail.com
}

\begin{abstract}
Theatre Pedagogy holds that cognition is body-based. Through performance the body's unconscious procedural memory learns. This information learned through repeated interaction with the world is transmitted to the brain where it becomes conscious knowledge. Theatre Pedagogy in this case study is based on the implementation of a Caribbean cultural art form in performance, in order to teach Francophone language and literature at the postsecondary level in Jamaica. This paper describes the experience of "doing theatre" with seven university students to learn the French language and literature based on an adaptation of two of Birago Diop's folktales. In the process of learning and performing the plays, the students also understood some of the West African cultural universals of life which cut across the lives of learners in their own and in foreign cultural contexts.
\end{abstract}

Keywords: Birago Diop, heritage folktale, cognition, theatre performance, theatre pedagogy

\section{Context}

The Caribbean is an artificially created space peopled at the service of colonization and the plantation system. Jamaica, like the other islands in the Caribbean, has a population of which the largest percentage is of African ancestry, since their forefathers were brought as slaves mainly, from West Africa. The slaves carried with them through the Middle Passage, not only their physical selves, but their language and culture which have been passed on orally, from generation to generation, resulting in the development of an Afrocentric Caribbean culture that is unconsciously owned and practised by the general populace.

Storytelling is unquestionably the art form of communication of the peoples of African descent. Its use can be detected in daily conversation, as well as in written creative works and theatrical performances. The storyteller in the Caribbean has his origin in the griot of West Africa (Hale, 1986). Just as song and dance are integral to the telling of tales in Africa (Ntuli, 2010), so too performances in dance and song are intertwined in the art of storytelling in the Caribbean (Creighton, 2009). 


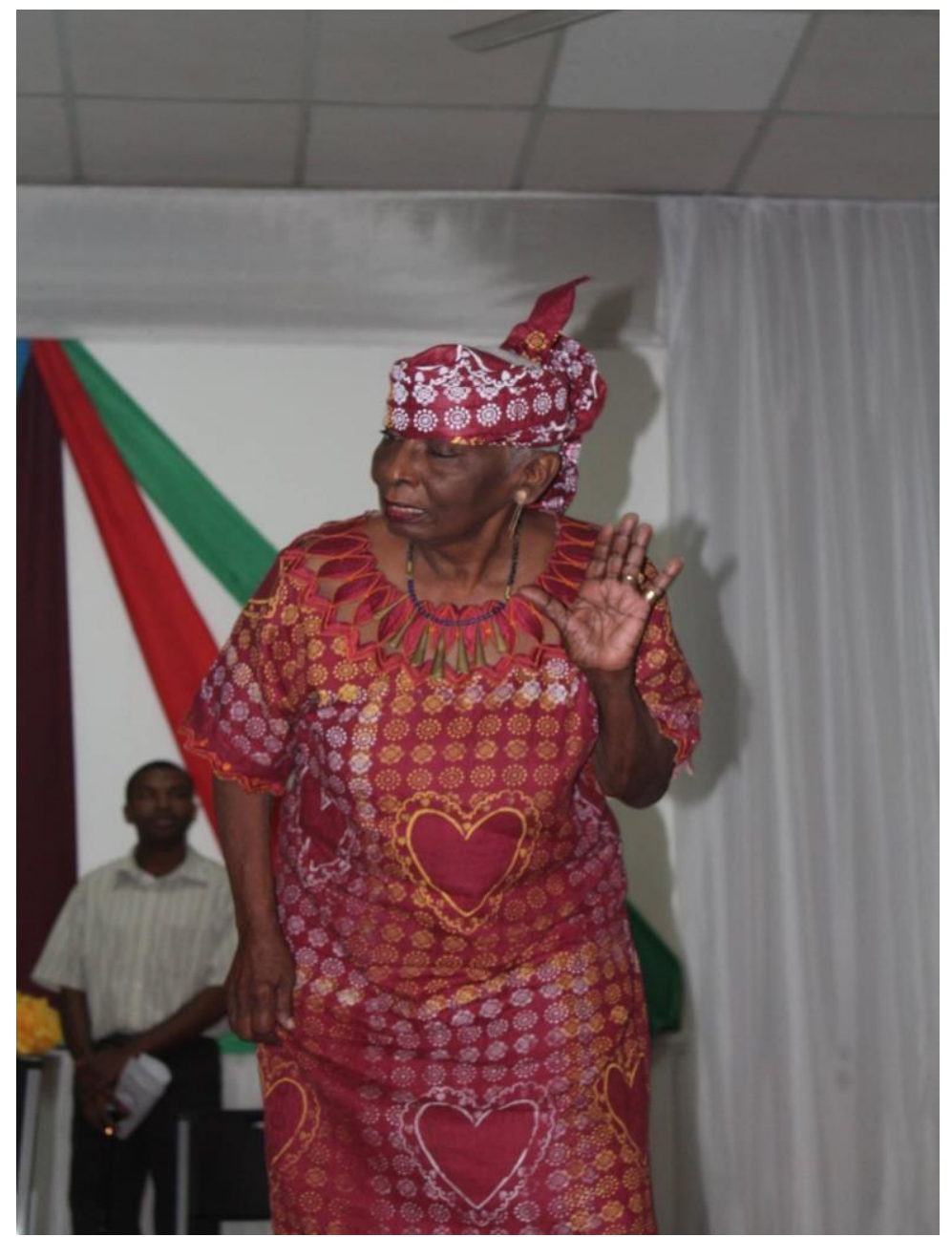

Figure 1. Caribbean Storyteller

Small, J. (2017). Performance of the folktale "La Reine des Anes".

Wong, S. (Photographer) (2017). La célébration de la Journée de la Francophonie. Performed at Shortwood Teachers College, Kingston, Jamaica.

Two of Birago Diop's folktales, Les Mamelles and Le Salaire in Contes Choisis (Diop \& Hutchinson, 1967), are central to this discussion. In teaching the university students Diop's folktales through Theatre Pedagogy, the objective was to get the students to "visualise the tales on stage." I wanted the students to have an intimate experience of owning a text through performance as well as being introduced to the life values of another culture conveyed through the message of the folk stories. Through the processes of learning and performing in French, the students were to understand the African ontology, the African theatre aesthetic, and the significance of the didactic nature of the folktale in an oral culture in which the mores of the society are passed on from generation to generation. Performance of a folktale allows for an entry into the effective use of silence, the fantastic and lyrical forms of linguistic expressions which constitute the communicative power of the storyteller. This article reveals that the most 
positive aspects of learning French through theatre are: the acquisition of a new vocabulary in real-life situations, the perfection of the pronunciation of the French language by virtue of frequent repetitions during a series of rehearsals, and as importantly, the solidarity of the members of the group that was built up through cooperation and teamwork.

\section{Introducing the Case Study}

In 1985, I initiated a programme called "the visualisation of literature." The objective was to perform on stage the literary works that students were studying so that they would have a more immediate experience and understanding of the text that was chosen for their final examination at the university. At the time of this project, the focus of the curriculum was French African or French Caribbean literature. Birago Diop's Folktales Les Mamelles and Le Salaire were the selected texts. I started the process with a call for students to participate in a staged production of the tales knowing full well that our Caribbean people are naturally given to dramatic expression. Nine students responded to the invitation to participate. I did not know them, nor did I know their French proficiency levels, as I was unaware of their grade levels. All I knew was that they were interested in acting in a French play. Primarily, that is all I ask at the beginning of "doing theatre" - that they want to do it. After a brief and passionate introduction on the structure and intention of the folktales (Propp, 1928), to guide me in selecting the cast, I had them read the text and do a little bit of singing because I intended to use songs in the production.

Why did I choose this approach to prepare them for their final examination? I believe that the theatre mode in the Caribbean is storytelling. I see storytelling at every street corner, at veranda gatherings, in the shops, and at funerals. The source of this natural talent is our traditional African heritage. I wanted the students to know intimately, through the use of their body language and their voices, the power of the role of the storyteller. This was not an easy task, at first, because the text I created seemed to be uncomplicated. I feared they might think that the plays were simple, and below their age group and comprehension levels, so as soon as they gained some competence in mastering the text, I re-engaged the services of the multifaceted, musician Mbala who was already part of the general and larger visualization project. He was invited to join the group to enable the students to appreciate the discourse between the text and the drum, similar to the way Niangoram Bouah (1981) conceived of "la drummologie." In this case, the actors would voice the text, and the drum and other musical instruments would engage in a discourse with the spoken word. There were times when the drum would have to speak in the place of the actor. Hearing the drumming, the students soon saw that the text I had created was not so simple and uncomplicated as a performance. 


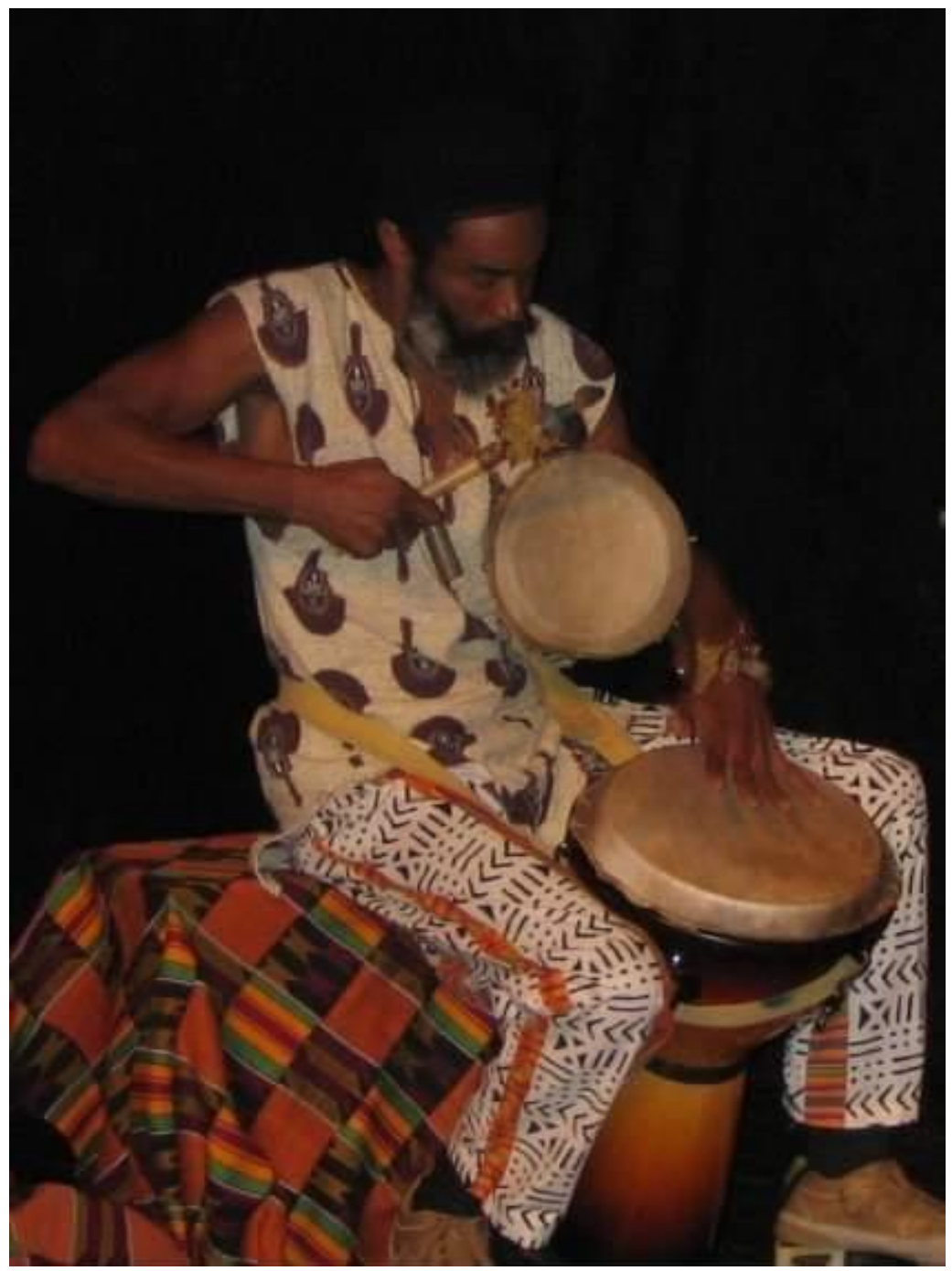

Figure 2

Mbala (1985). Jamaican poet drummer and maskmaker.

Project photograph (1985). Mona Campus, University of the West Indies, Jamaica.

\section{Presenting the Setting of the Folk Stories in Theatre Pedagogy}

The context of the tales is a tropical setting to remind us that our ancestors came from West Africa, a predominantly agrarian environment. Our animal tales are set in the forest inhabited by animals that are strangely similar to commonplace human types. Familiar physical symbols are constructed and used in the scenery of the set such as, a natural mound in the terrain, a bamboo hut, and real gourds are laid strategically on the ground. The bright colours of the surrounding vegetation and costumes evoked the culture. A central feature in the set was a tamarind tree, representative of source and origin for as the griot said, 'L'arbre ne s'élève qu'en enfonçant ses raciness dans la terre nourricière" (the tree grows by force of sinking its roots in the land that nourishes it). This tree symbolized our rootedness in the culture of our African 
ancestors. The tamarind tree in West Africa, like the cotton tree in Jamaica, is the abode of the spirits. It is therefore a sacred tree; one to be respected. The presence of "la brousse" (bush) on all sides of the performance space/a natural stage indicated the closeness of man to nature. Although this performance took place in a natural environment, it was unfortunate that this performance could not have taken place, "in the round" because spatial organization is one of the essential elements of the African theatrical aesthetic. Students, therefore, did not experience this aspect of African theatre in which the audience sits on the ground around the acting space which allows audience members to move in and out of the performance, if they so desire. This interaction is impossible with the proscenium arch-type of setting that we used (a format familiar to the students). In the performances, the audience sat in the natural environment but at some distance away from the performance space. In the African theatre, the subject of discussion in a play or a tale is usually one that concerns the entire community and so, of necessity, members of the audience have an instinctive inclination to get up and participate in the performance. The students, however, did not experience this type of participatory theatre which is typically African. For the play, I created the character of a griot (Hale, 1986) to be the link between the tales. This character is not identified in the original text by Birago Diop, although he gives an extensive description of the place and function of the griot in French West African culture. There is a wide vocabulary surrounding the griot as the repository of the wisdom and history of the clan. So in this attempt at "griotisation," I as "griotiseur" created a griot to be something of a narrator/director, giving explanations when they were required and commenting on the action of the tales. The centrality of the griot was shown in his descending from the mound to a central position on the stage, at the beginning of the play. He was seated, in silence, while the drums, the flutes, the shak-shaks, the mbira, and the tambourine told the entire story of the two tales in the form of an overture (a composition of all the accompanying music used throughout the entire production of the two tales). The music would then, be easily recognized later during the production when it was played again. The griot composed what may be called "grio-poems," speaking and chanting them ritualistically, appeasing the Gods so that all should go well; calling for "Vérité," for the truth to be told, and assuring the Gods that this beautiful race of black people would not bring shame to them. The griot chanted:

"Vérité oh

Vérité oh

\section{Le Bon Dieu aime}

\section{La Vérité oh".}

The chant created for the griot was intended to remind the students of the ritualistic nature of storytelling, for the space has to be cleansed, for the truth that would be told. At one time, the musical rhythms accompanied his poetic lines; at another they were interspersed with his spoken words. There was the feeling of the "call and response" between his voice and the musical instruments, a form that is so characteristic of African music. The griot lumbered off stage, heavy with the weight of his wisdom as the tale began. 


\section{Presenting the Two Folktales}

\section{Les Mamelles}

The first tale is an explanatory story of a physical phenomenon, the existence of the mountains Les Mamelles which were provided with that name because they look like two breasts of a woman. How did they get that shape and why are they jutting out of the sea? This tale helped the actors to understand polygamy and what causes a man in that culture to take a second wife. The play explored what attributes a man values in a wife, and highlighted the ensuing relationship between the two wives. It is generally believed that co-wives live happily together sharing the same husband. This tale, however, showed that is not always the case, and further, that envy and jealousy are not pleasing to the Gods. The presence and the influence of the supernatural are very strong in this culture. The message is that Man, Gods, spirits and nature are closely bound and one has to heed the voice of all that is present in the universe. There is an explanation, at another level, that good is rewarded as in the case of the caring wife and bad is punished as in the case of the wife who allowed her physical handicap to prevent her from being the kind of wife that the husband wanted. In a non-scribal culture, the telling of tales is essentially an educational act and is therefore legitimately orature, the alternative to literature, the written text or the book.

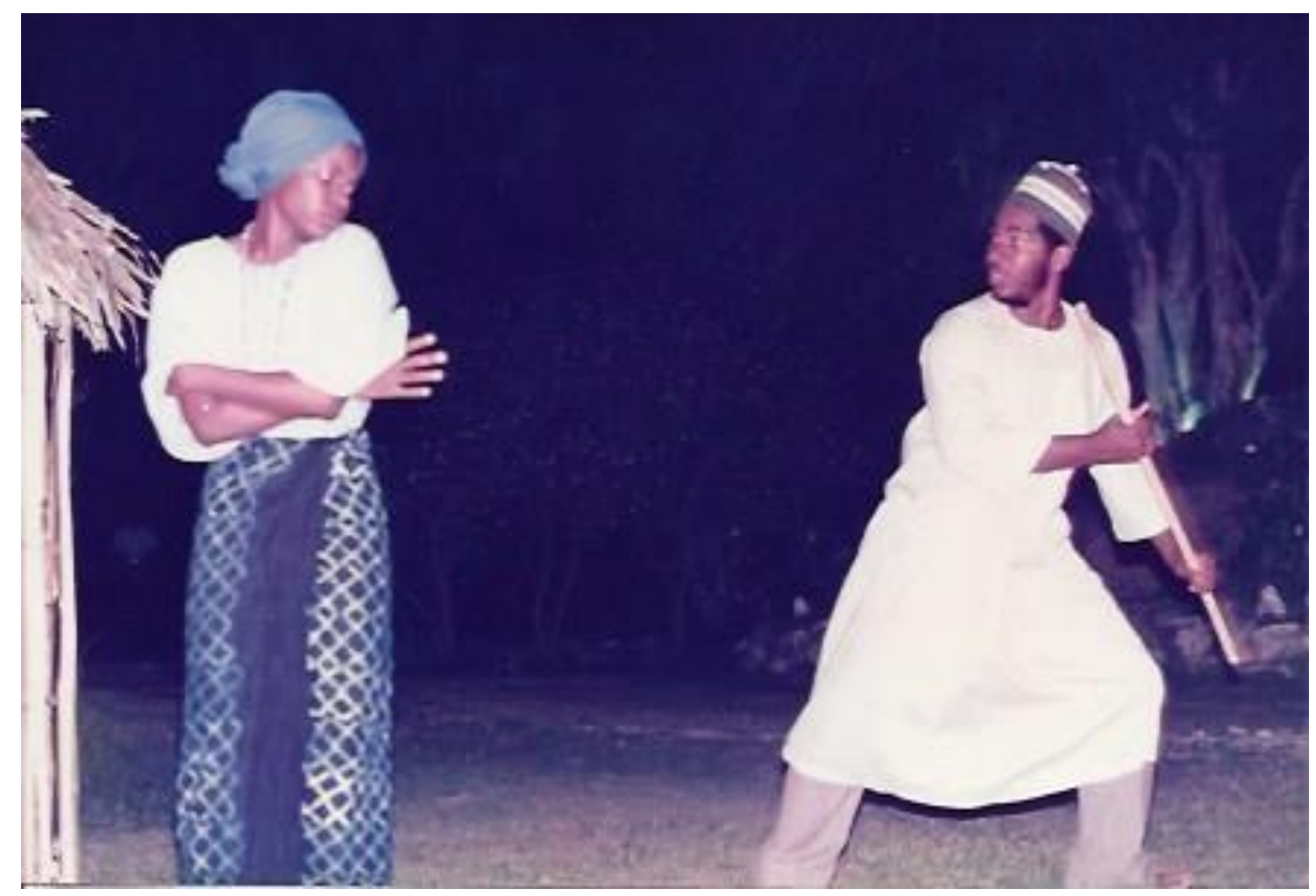

Figure 3

Project photograph (1985). Les Mamelles. 


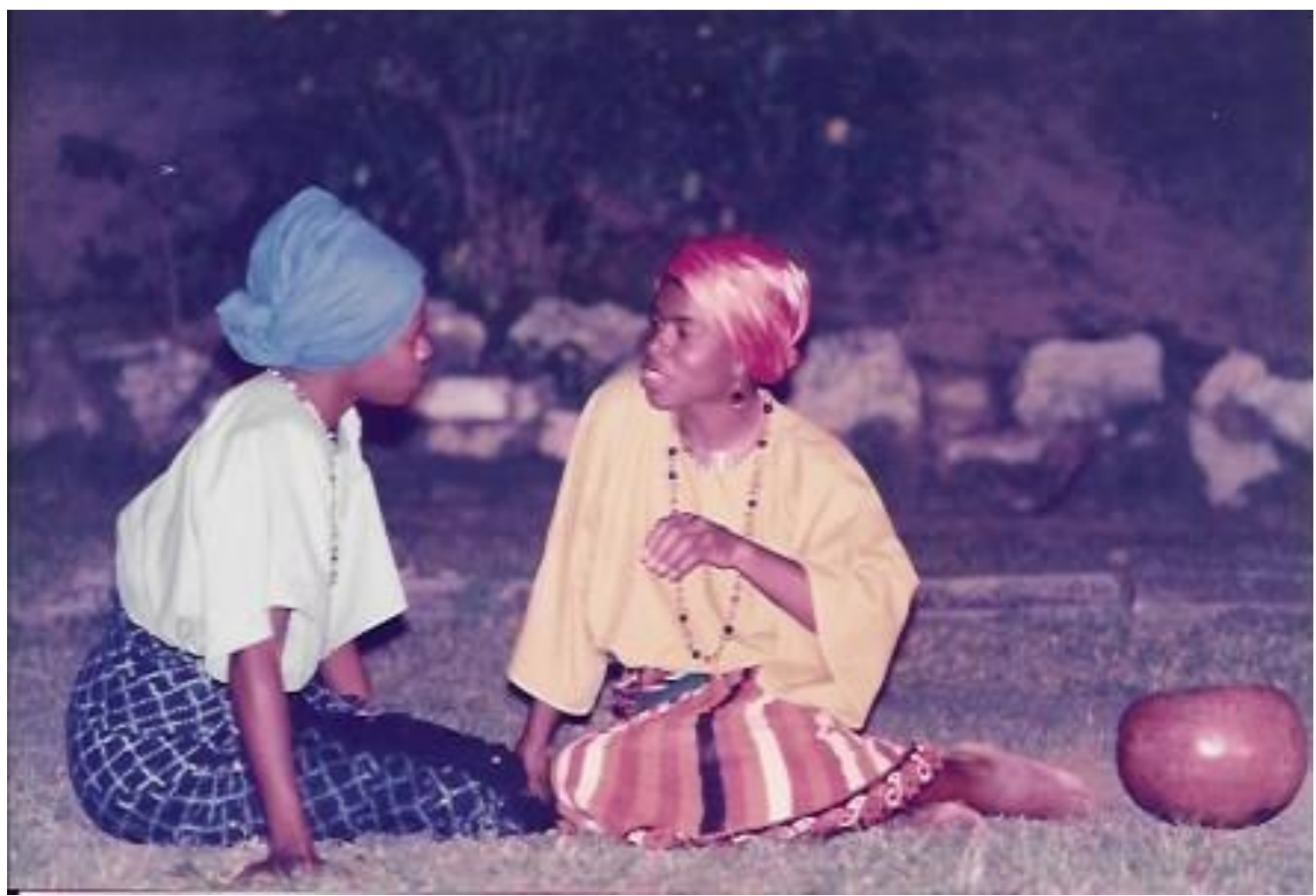

Figure 4

Project photograph (1985). Les Mamelles.

The colours used for the wives costumes spoke volumes - Blue was used for the unhappy, miserable first wife who felt abandoned by God. In contrast, there was with the sunfilled yellow costume of the second happy wife. These colours were chosen to emphasise the opposition between the two wives.

The only character that was dressed in white was the griot. White is worn in this case, by the one who establishes truth. The grandeur of his role was expressed through the brilliance and expanse of the white boubou that he wore and the necklaces which seemed to embody special powers. These affected his gait and gave the lines that he uttered and the chant that he sang awesome significance. The student immediately, became the griot.

\section{Le Salaire}

The second tale is an animal tale in which the animals take on the characteristics of human beings with unique life experiences (Fischer, 1963). The King's daughter who went out walking got lost in the swamp. An order was given to have all the swamps drained and dried up and all the crocodiles killed. The daughter's body was found at the bottom of the hole of Diassigue, the oldest crocodile, who having been displaced, was wandering about lost in the bushes.

Diassigue, the crocodile, begs a boy passing by to help him to the river. 


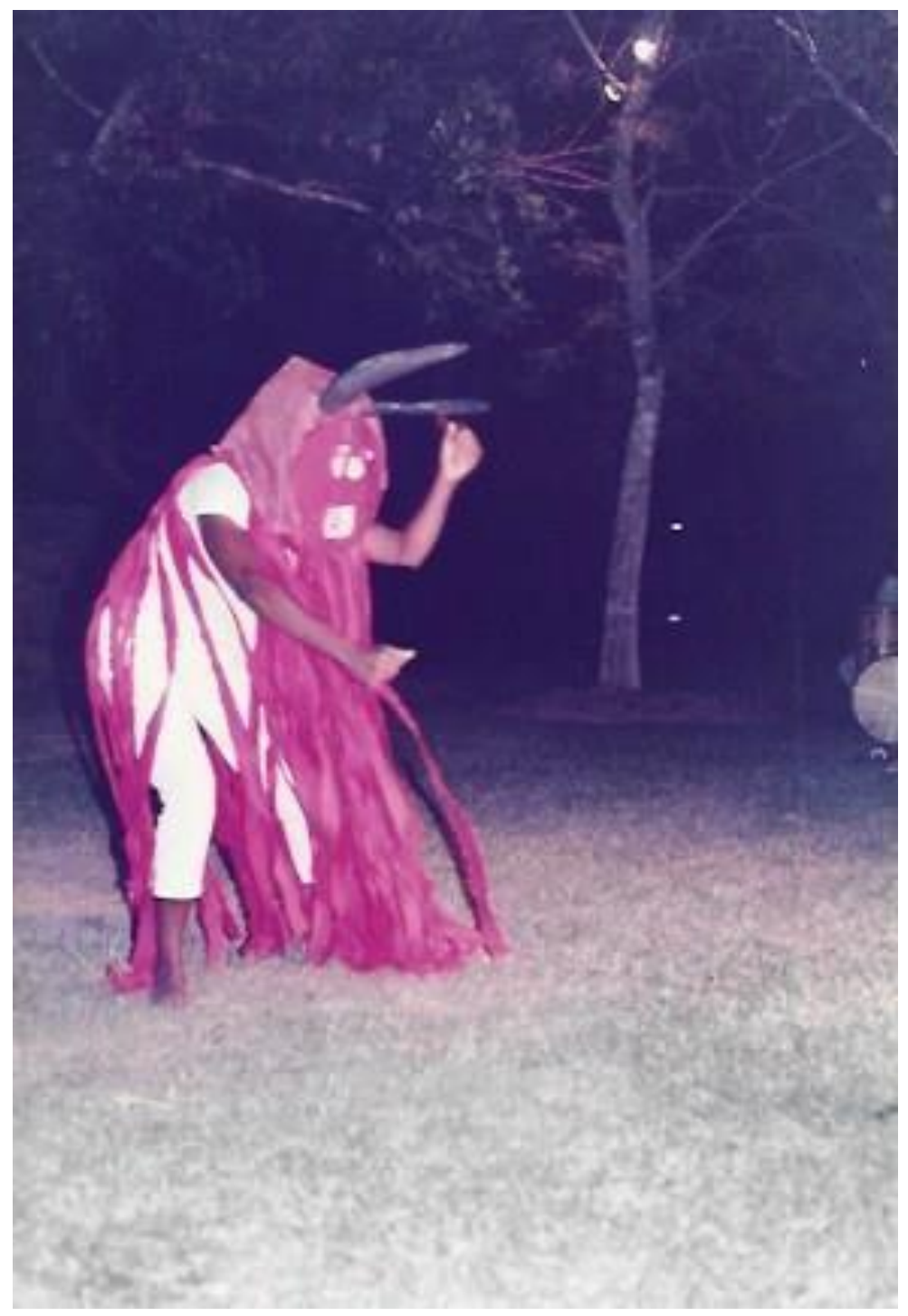

Figure 5. Diassigue the crocodile Project photograph (1985). Mask created by Jean Small.

After Gone had taken him safely to the river, Diassigue dying of hunger, by this time, turned around to try to eat the boy. The question is, when you do a good act for someone, what do you get in return? Another good turn or a misdeed? Hare looking on at the situation resolved the problem by tricking the crocodile to become the meal eaten by the boy and his family instead of the other way around.

The trickster Hare is a parallel character with our own anti-hero, trickster character Anansi, who in the folktales is always amused when punishment is meted out to the dishonest and ungrateful. The theme of displacement seen in the crocodile, who was forcefully dislodged from his hole, is a common one in Caribbean literature because loss has been one of the traumatic experiences in the history of the people, in the African diaspora. Diassigue the 
crocodile, used to being in water, finds himself in the bush. He is in strange territory and cannot find his way. He wants to go back where he belongs very much like the back to Africa repatriation movement in the Caribbean. This story is a most appropriate way of understanding topics such as loss, displacement and repatriation. Participating in the performance of a tale, such as this, allows the student/actor to reflect on a situation that is similar to real-life. To temporarily become an animal and play out such themes as displacement, migration, repatriation, exploitation of the other, interdependence of man and animal, justice and injustice is considered an experience of cathartic cleansing.

Masks were made for the student/actors who portrayed the animals, but the masks were not realistic in design. They, however, had a magical effect on the body language as well as the voice of the actors. It became quite believable to the actors that man and animal can consort and communicate in this world of the "fabulous".

\section{Summarizing the Impacts and Outcomes of Theatre Pedagogy}

What were the impacts of Theatre Pedagogy on the students? Firstly, the actors learned to work in harmony with the music. In turn, the music complemented the performance of the actor as exemplified at the opening performance when an actor had a nervous "trou de mémoire," the drums spontaneously came in, filled the gap and helped the actor to regain composure. That was perhaps the best example of co-operation between voice and musical instruments.

Secondly, sound and music was a key language in this production and the students/actors learned to combine them for wordless expressions. The musician created sounds to accompany the moods and the body movements of the characters. There were sounds that described for example, tiredness at the end of the day, anger, jealousy, busy activity, wading through water, the moo of a cow, the neigh of a horse, and the slow rhythmical movement of a female carrying a heavy load on her head. Perhaps, best of all, were the drums' sounds to represent: (i) the man who is attracted to a woman, who decides to take her as his second wife, and (ii) the wife lovingly caring for her husband. The acting experiences were the students' introduction to total theatre in which the elements of the spoken word, dance, music, poetry and prose came together in harmony for communication.

All of the preceding elements testify to the ability of the folktale to discuss literary themes, to teach the moral code of a culture and to integrate word, music, movement and gesture for understanding and communication. The students understood better the meaning of touching the soil as an act of appreciation rather than bowing to the audience. It is as culturally important as the language of the hands gesturing, "I wrap him around and tie him up" to express the love act.

Thirdly, there were also personal discoveries. We found in the process that there were no final year students in the cast. Three were, in fact, beginning their university studies. Yet, the students were complimented for their clear articulation and good pronunciation. Students who had problems with some of the words and expressions in the text had an excellent opportunity by repeating them during the many "répétitions" (rehearsals) to work hard for perfection. Once, the students knew that they had mastered the correct pronunciation, they developed a sense of confidence which was carried over to their course work as was evidenced in the excellent performance in their final oral examinations. The most rewarding outcome of learning through 
performance in this way was to hear the students talking among themselves, in French, offstage using expressions from the text which they incorporated in their own conversational vocabulary.

Fourthly, another positive effect of theatre pedagogy on the linguistic side is the number of new words that the students had learned such as:

vérité, mamelles,bosse,bossu(e), tam, mépris, canaris, nanas, têter, fille-génie, calebasse, marigot, caïman, méchanceté, natte, ficelle, ficeler, bonté, palfrenier, barbotage, auge, bride, cordonnier, croupe, entrave, brousse, bambin, forgeron, and expressions such as, avoir le coeur noir comme du charbon, être aigre et acide comme du lait qu'un génie a enjambé, avoir la voix aigre et acide comme le jus du tamarin, en plein jour, je t'en sais digne, le point culminant, puiser de l'eau, recurer les calebasses, lâche-moi.

Fifthly, feedback from the students was mainly positive. Some said they would never forget the words and expressions they had learned because they discovered the meanings in a practical context. The structure of the folktale, which is one of repetition based on the numbers 3 and 7, allowed for pleasant and entertaining reinforcement of language and song.

Finally, the students all made new friends because they were strangers before the project started. They learned to be respectful of each other's time by arriving on time for rehearsals and apologizing to everyone if they were late. They learned to work together, to co-operate, to be tolerant of each other's weaknesses and in the process to help each other improve. They learned to pick up the slack when it was necessary to do so; they learned to share ideas and the director learned to respect and accept their ideas in turn. As this was strictly educational theatre and not commercial theatre, the project had limited financial resources for realizing the performances, so we learned to use what we had or be creative. The performances were intended for the student body with the aim of joyfully sharing expression in the foreign language. The cast did not have a stage manager, a costume mistress, or a property master. The director and actors had to do everything themselves which involved: cutting branches to represent the bush and also, fetching stones for the stage, ironing costumes, fetching drums and other musical instruments back and forth, dismantling the set at the end of each performance and setting it up for the next performance. From this small but important experience, this group of seven students built up such a strong spirit of camaraderie and a sense of pride in their achievements that they expressed the desire to remain together as a French Theatre Troupe. 


\section{References}

Creighton, A. (2009, August 16). The African storytelling tradition in the Caribbean. Stabroek News. Retrieved from: https://www.stabroeknews.com/2009/sunday/arts-onsunday/08/16/the-african-storytelling-tradition-in-the-caribbean/

Diop, B. I., \& Hutchinson, J. A. (1967). Contes choisis. J. A. Hutchinson (Ed.). UK: Cambridge University Press.

Fischer, J. L. (1963). The sociopsychological analysis of folktales. Current Anthropology, 4(3), 235-295.

Hale, T. A. (1986). Griots and griottes: Masters of word and music. Bloomington: Indiana University Press.

Niangoran-Bouah, G. (1981). Introduction à la drummologie. Abidjan: G.N.B., Ivory Coast.

Ntuli, C. D. (2010). The function of songs in the performance of Zulu folktales. Muziki: Journal of Music Research in Africa, 7(2), 216-227. Published online.

Propp, V. (1928). Morphology of the Folktale. Leningrad, Russia: Academia. 
Jean Small, PhD, Chevalier de la Légion d'honneur
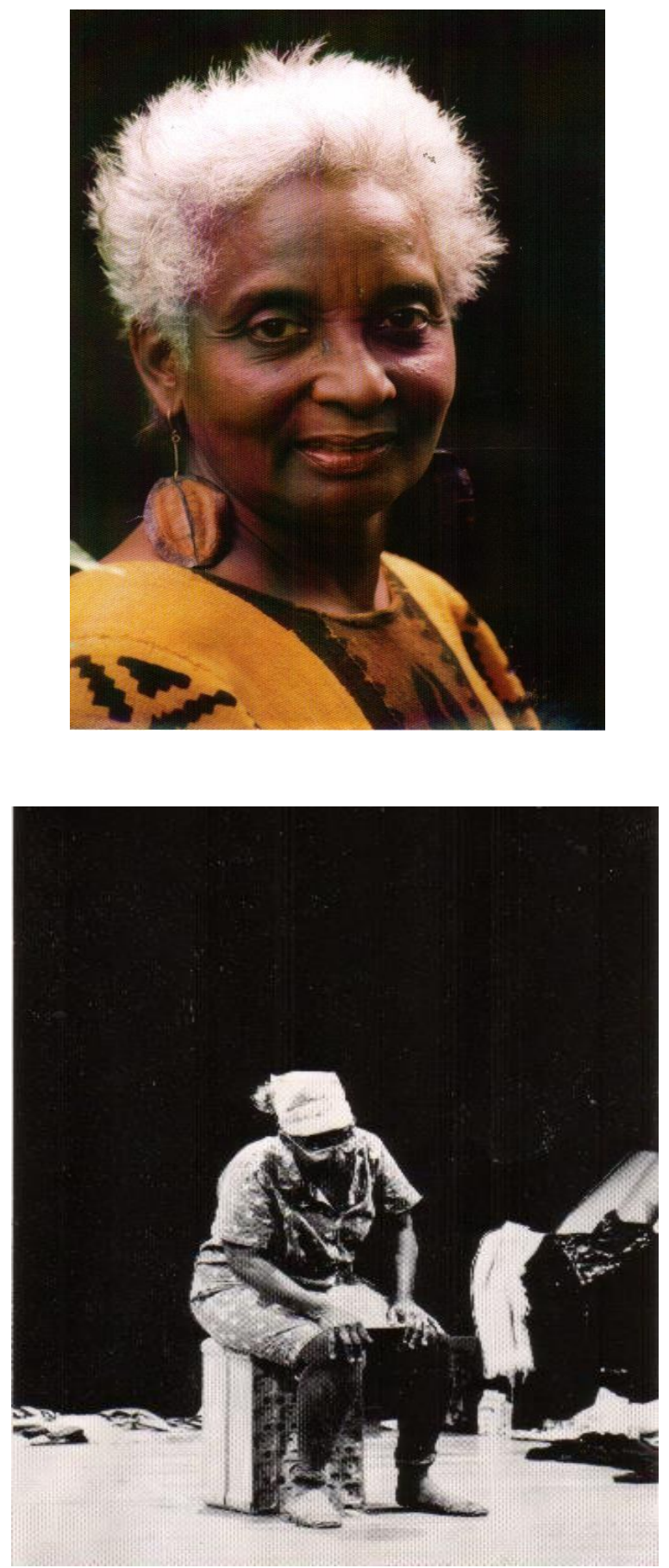

Small, J. (1990). Le Conte d'une Femme Noire. Kingston, Jamaica. 